This is an electronic reprint of the original article. This reprint may differ from the original in pagination and typographic detail.

Author(s): Boulay, Raphael; Galarza, Juan; Cheron, Blandine; Hefetz, Abraham; Lenoir, Alain; Oudenhove, Louise Van; Cerda, Xim

Title: Intraspecific competition affects population size and resource allocation in an ant dispersing by colony fission

Year: $\quad 2010$

Version:

Please cite the original version:

Boulay, R., Galarza, J., Cheron, B., Hefetz, A., Lenoir, A., Oudenhove, L. V., \& Cerda, X. (2010). Intraspecific competition affects population size and resource allocation in an ant dispersing by colony fission. Ecology, 91(11), 3312-3321.

https://doi.org/10.1890/09-1520.1

All material supplied via JYX is protected by copyright and other intellectual property rights, and duplication or sale of all or part of any of the repository collections is not permitted, except that material may be duplicated by you for your research use or educational purposes in electronic or print form. You must obtain permission for any other use. Electronic or print copies may not be offered, whether for sale or otherwise to anyone who is not an authorised user. 


\title{
Intraspecific competition affects population size and resource allocation in an ant dispersing by colony fission
}

\author{
Raphä̈l Boulay, ${ }^{1,2,7}$ Juan A. Galarza, ${ }^{1}$ Blandine Chéron,${ }^{3}$ Abraham Hefetz, ${ }^{4}$ Alain Lenoir, ${ }^{5}$ \\ Louise van Oudenhove, ${ }^{1,6}$ and Xim Cerdá ${ }^{1}$ \\ ${ }^{1}$ Estación Biológica de Doñana, CSIC, Seville, Spain \\ ${ }^{2}$ Universidad de Granada, Granada, Spain \\ ${ }^{3}$ Laboratoire Écologie et Évolution UMR CNRS 7625 , Paris, France \\ ${ }^{4}$ Tel Aviv University, Tel Aviv, Israel \\ ${ }^{5}$ IRBI, Université Francois Rabelais de Tours UMR CNRS 6035, Tours, France \\ ${ }^{6}$ LBBE, Université Lyon I UMR CNRS 5558, Lyon, France
}

\begin{abstract}
Intraspecific competition is a pervasive phenomenon with important ecological and evolutionary consequences, yet its effect in natural populations remains controversial. Although numerous studies suggest that in many cases populations across all organisms are limited by density-dependent processes, this conclusion often relies on correlative data. Here, using an experimental approach, we examined the effect of intraspecific competition on population regulation of the ant Aphaenogaster senilis. In this species females are philopatric while males disperse by flying over relatively long distances. All colonies were removed from 15 experimental plots, except for one focal colony in each plot, while 15 other plots remained unmanipulated. After the first reproductive season, nest density in the experimental plots returned to a level nonsignificantly different from that in the control plots, which was not expected if the populations were indeed regulated by density-independent phenomena. In both the control plots and the experimental plots colonies remained overdispersed throughout the experiment, suggesting colony mutual exclusion. Nests outside the plots rapidly extended their foraging span, but we did not detect any significant inward migration into the experimental plots. Experimental reduction in density did not significantly affect the focal colonies' biomass, measured just before the first reproductive season. However, the ratio of males to workers-pupae biomasses was smaller in experimental plots, suggesting that colonies there had redirected part of the resources normally allocated to male production to the production instead of new workers. Microsatellite analysis indicated that, after the reproductive season, many colonies in the experimental plots were headed by a young queen that was the mother of the brood but not of the old workers, indicating that reduction in colony density stimulated fission of the remaining colonies. Finally, at the end of the experiment, 14 months after experimental reduction in density, colonies that derived from fission were smaller in the experimental than in the control plots, suggesting that the former had undergone fission at a smaller size than in control plots, which presumably allowed them to colonize the emptied areas. We conclude that colonies adjust resource allocation and colony fission to the degree of intraspecific competition.
\end{abstract}

Key words: ants; Aphaenogaster senilis; density dependence; population growth; resilience; resource allocation.

\section{INTRODUCTION}

The importance of density-dependent processes in the regulation of natural populations is a matter of prolonged debate with profound implications in basic and applied science (Krebs 2002, Berryman 2004, Balbontín and Ferrer 2008, Carrete et al. 2008). The assumption that population growth rate decreases when population density increases seems reasonable for most organisms. However, the impact of intraspecific competition on wild populations may be masked by a set of

Manuscript received 19 August 2009; revised 4 January 2010; accepted 31 March 2010. Corresponding Editor: D. A. Holway.

${ }^{7}$ E-mail: boulay@ebd.csic.es important density-independent factors, including climate change and habitat perturbations (Sæther et al. 1999, Sanders and Gordon 2004, Pellet et al. 2006). A negative feedback between population density and population growth rate can derive from two nonexclusive phenomena. First, per capita access to resources is likely to decrease with the increasing number of individuals, which would limit reproduction and/or survival (Amundsen et al. 2007, Therrien et al. 2007, Branson 2008). Second, neighbors may tend to aggressively exclude aliens in order to protect space-linked resources such as territories or nesting sites (Gordon 1997, López-Sepulcre and Kokko 2005). As a result, populations at equilibrium under strong intraspecific 
competition are often composed of established individuals that are overdispersed and monopolize all the available space (Iguchi and Hino 1996, Nilsson 2006, Boulay et al. 2007a). By contrast, if other mechanisms than intraspecific competition regulate populations, one may expect individuals to be either distributed randomly or aggregated, while using only a fraction of the available space.

One experimental approach to testing the effect of intraspecific competition on population growth comprises removing (or adding) individuals and monitoring subsequent population variations (Murdoch 1970, 1994, Massot et al. 1992, Adams and Tschinkel 2001, Honarvar et al. 2008). A population regulated by intraspecific competition is predicted to be resilient to this kind of manipulation and to return rapidly to its initial state. The possible involved mechanisms include the immigration of neighbors to the free area, and enhanced survival and reproduction of the remaining individuals. In many organisms, there are trade-offs between immediate and future reproduction and between offspring number and quality (Stearns 2000). Therefore, under crowded, highly competitive conditions in which offspring success is uncertain, adults may tend to delay reproduction in order to provide offspring with enough resources without jeopardizing future reproduction. By contrast, adults may take advantage of less crowded conditions to produce larger numbers of lower-quality offspring, thus contributing to population recovery (Leips et al. 1997, Waelti and Reyer 2007).

Intraspecific competition is also expected to affect sex allocation (Hamilton 1967, Charnov 1982, Crozier and Pamilo 1996). For example in species in which only the males disperse, while the females remain near their birthplace, the production of female offspring may be less beneficial in crowded conditions, because daughters added to the population will compete for resources among relatives, which reduces their value for the parents. By contrast, if competition is relaxed due to an increase in food availability or a reduction of population density, female offspring become more valuable and parents are therefore expected to allocate more resources to their production (Bourke and Franks 1995, Crozier and Pamilo 1996, Brown and Keller 2006).

The aim of the present study was to test the effect of intraspecific competition in regulating female populations in a species with male-biased dispersal: the ant Aphaenogaster senilis (see Plate 1). The female unit consists of a colony composed of one reproductive female, the queen, and several hundred sterile workers. Young queens have wings too short to be able to fly, and thus reproduction and dispersal are through colony fission, whereby the queen and a group of workers leave their mother nest on foot, and found a colony in the near vicinity (Ledoux 1971, Boulay et al. 2007b; J. A. Galarza, unpublished data). Males, in contrast, have well-developed wings and disperse by flying away from their nest a few days after emergence.
The effect of intraspecific competition has been studied in several ant species by correlating density with nest distribution (Elmes 1974, Ryti and Case 1986, Cushman et al. 1988, Adams and Tschinkel 1995b), reproduction (Ryti and Case 1988, Gordon and Wagner 1997), recruitment of new colonies (Adams and Tschinkel 1995a, Cole and Wiernasz 2002), and mortality (De Vita 1979, Gordon and Kulig 1998). Fewer studies have experimentally tested density-dependent population regulation in ants. Resilience experiments have been conducted with the North American harvester ants Veromessor pergandei, Pogonomyrmex californicus (Ryti and Case 1988), and P. occidentalis (Billick et al. 2001), as well as the red imported fire ant, Solenopsis invicta (Adams and Tschinkel 2001). The first two studies concluded that a reduction in density provoked an increase in sexual production and enhanced the recruitment of new colonies, respectively. In the fire ant, Adams and Tschinkel (2001) also observed an augmentation of incipient colony survival along with an important inward migration of neighboring colonies, leading to population recovery.

Here, we present the results of a resilience experiment in which we reduced $A$. senilis population density in 15 experimental plots, leaving a single focal colony per plot, while density remained unmanipulated in 15 control plots. Based on the previously mentioned studies we predicted that if intraspecific competition indeed regulates populations, (1) they would be resilient to density perturbations, that is, density reduction in the experimental plots would be followed by a rapid recovery in the number of nests; (2) nests in both the control and the experimental plots before the onset of the experiment and after population recovery would be overdispersed; (3) density reduction would enable the remaining colonies to expand their foraging areas; (4) density reduction would enable colonies to migrate more often and, for colonies located outside the density-reduced plots, to migrate inward. Moreover, because dispersal is male-biased, we expected that the lack of competitors would stimulate the production of daughter colonies. Specifically, we predicted that (5) density reduction would increase colony productivity and/or would provoke a reduction of resource allocation for male production in favor of workers, thus preparing colonies to undergo fission; and (6) the remaining colonies (including focal colonies and their neighbors) would fission more often and at an earlier stage, thus producing smaller daughter colonies than under the control conditions. In order to test these hypotheses, following density reduction the number of colonies, their distribution, biomass, and foraging span were monitored at various time intervals throughout one year. We also conducted a microsatellite analysis to estimate colony reproduction rate. We took advantage of the fact that colonies that form by fission subsequently produce new queens through reorientation of bipotent larvae and are thus composed of two worker cohorts with different 


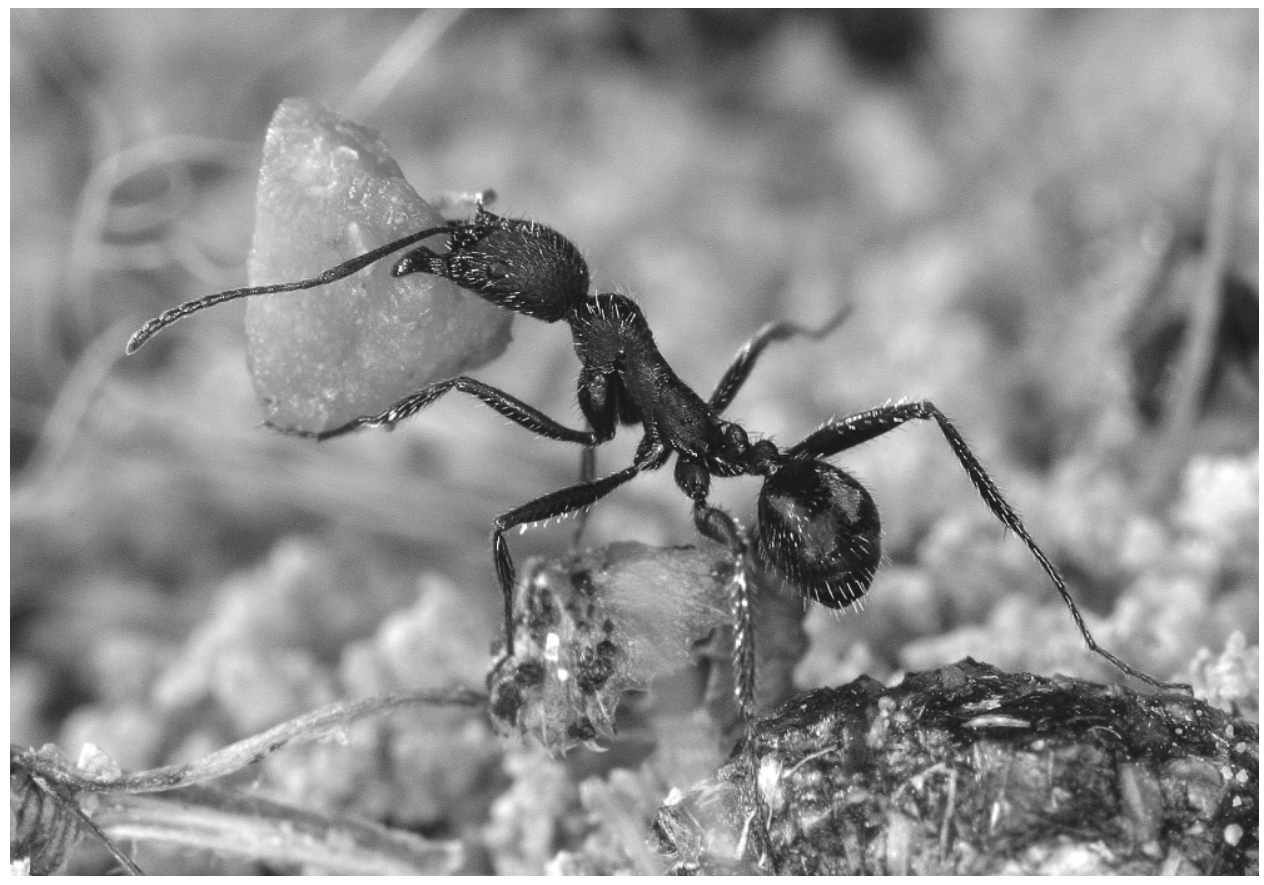

Plate 1. An Aphaenogaster senilis forager returning to her nest with a seed of Arum italicum. Photo credit: Fernando Amor.

levels of genetic relatedness: old workers that are sisters of the new queen $(r=0.75)$, and young workers that are her nieces $(r=0.375)$. Therefore, if density limits colony reproduction (prediction 6), we expected that the average relatedness in density-reduced plots would be lower between than within cohorts.

\section{Materials and Methods}

\section{Model species and study site}

Aphaenogaster senilis is a common ant species in the Iberian Peninsula. It is a subordinate species that feeds on a wide variety of spread food items including live and dead arthropods and seeds. It can forage at relatively high ground temperature, which reduces competition with dominant species of the genus Tapinoma, Tetramorium, and Lasius that forage at cooler temperature. Colonies of $A$. senilis are strictly monogynous and monandrous (Boulay et al. 2007b, Chéron et al. 2009) and contain on average $1260 \pm 69$ monomorphic workers (mean $\pm \mathrm{SE}$; length, 6-10 $\mathrm{mm}$; mass, 5-8 $\mathrm{mg}$ ). Most worker brood is produced in spring (AprilJune), which results in a significant increase in the colony worker population in July. Colony fission generally occurs in the second part of the summer, and is followed by a small reduction in average colony size. Thereafter, worker population remains constant throughout the autumn and winter but declines in April, probably because of the death of workers born in the previous year (Boulay et al. 2009).

The study was conducted in the research reserve of the Doñana National Park (South Spain). Four subpopula- tions (hereafter demes) were selected 0.9 to $6 \mathrm{~km}$ apart (Comedero, Visita, Beles, and Jaulon) in sandy areas $\sim 4$ $\mathrm{km}$ from the coastline: Visita, Beles, and Jaulon consist of open shrubland composed mainly of Halimium halimifolium, Halimium commutatum, Stauracanthus genistoides, and Lavandula stoechas, while Comedero presents the same shrub species along with a scattering of pine trees (Pinus pinea) and savin juniper trees (Juniperus sabina).

\section{Characterization of focal colonies and reduction of nest density}

In March 2007 (one month before nest density reduction, $M_{-1}$ ), 30 colonies, at least $60 \mathrm{~m}$ apart, were selected in the four demes (four at Comedero, six at Visita, 16 at Beles and four at Jaulon) as focal colonies. These were carefully excavated and brought to the laboratory, where the workers and brood were weighed and 400 workers and the queen were marked with a dot of white paint (Mitsubishi Pencil, Shinagawa-ku, Tokyo, Japan) on the abdomen. The colonies were then released back at the site of capture. After they had settled down in a new nest, about a week later, $18 \times 18 \mathrm{~m}$ plots were delimited around them. The entire number and location of nests within the plots and in an outer band of $3 \mathrm{~m}$ width was then surveyed using 25 food baits (biscuits) deposited in a regular pattern on the ground. Each bait was inspected twice by two to four observers over a period of three hours in order to track foragers back to their nests.

In one-half of the plots, all the focal colony neighbors within each plot were carefully excavated in April 2007 
$\left(M_{0}\right)$, so that the closest neighbors of each focal colony were in the outer band at least $9 \mathrm{~m}$ away. To ascertain complete removal of the neighboring colonies, the same procedure was repeated a week later. The 15 control plots remained untreated.

\section{Population monitoring}

The number of colonies and their nest locations were exhaustively surveyed in April, May, June, August, and October 2007 and April $2008\left(M_{0}, M_{1}, M_{2}, M_{4}, M_{6}\right.$, and $M_{12}$, respectively) using the previously mentioned baitscreen procedure. In addition, the presence of ants in previously occupied nests was monitored every week during the first 20 weeks (until mid-July 2007). For unoccupied nests, whenever a new nest was located within $3 \mathrm{~m}$ from the deserted nest we assumed that it belonged to the same colony that had migrated to the new location; otherwise we assumed that the colony had migrated farther than $3 \mathrm{~m}$. All nests were geo-referenced using a Leica gs20 GPS (Heerbrugg, Switzerland). Nest positions were post-processed using Leica GIS Data Pro and a fix position situated at San Fernando (Cadiz province), $\sim 50 \mathrm{~km}$ from our plots. Absolute and relative nest positions were obtained with errors $<50$ and $20 \mathrm{~cm}$, respectively.

Marked old workers in the focal colonies progressively died between March and June 2007. We therefore periodically marked additional foragers of focal colonies in situ without excavating the nests, which enabled us to properly identify and re-excavate 16 focal colonies (from seven experimental and nine control plots) in July 2007 $\left(M_{3}\right)$, just after the peak in brood production. These colonies were brought to the laboratory where their worker and brood biomasses were recorded. Thereafter they were again released at the spot of capture.

During the last exhaustive census (April 2008), a total of 647 individuals (464 adult workers and 183 pupae) were collected from 84 nests located inside 11 control and 11 experimental plots from Comedero, Beles, and Visita. Because by this time no marked worker was still alive, and the focal colonies had migrated several times since the beginning of the experiment, we were not able to determine a priori whether some of the sampled colonies included the focal colonies. Only pupae stored in upper nest chambers were sampled, by simply scratching the surface. No pupae were available for 14 nests in the control and 20 nests in the experimental plots. For each nest, 4-7 workers and/or 3-6 pupae were genotyped at seven species-specific (Galarza et al. 2009) and one cross-amplified (Arthofer et al. 2005) polymorphic unlinked microsatellite markers. DNA extraction and amplification conditions were carried out as described in Galarza et al. (2009). At the end of Aprilbeginning of May 2008, 32 colonies from which we had previously collected both workers and pupae were excavated in experimental and control plots. They were brought to the laboratory to determine their worker and brood biomasses.

\section{Data analysis}

General procedure.-Focal colonies were well identified and at a sufficient distance from each other $(>60 \mathrm{~m})$ to be considered independent experimental units. By contrast, their sets of neighbors were not individually identified and were not independent among them. Therefore, longitudinal data on neighbors' behavior were averaged per plot and month and the statistical analyses were conducted on these averages, using the plot as the statistical unit. General linear mixed models (GLMM) were fitted to the data using the lme command (for linear mixed models) from the Linear and Nonlinear Mixed Effects Models (nlme) R package version 2.8.1 (R Development Core Team 2009). Plots (or focal colonies) nested within demes were considered random effects. Contrast analyses ( $t$ statistics) were conducted to test the significance of pairwise differences among levels of significant fixed effects. Otherwise, nonparametric statistics were used for comparisons between control and experimental groups. All estimates are mean \pm SE.

Nest number (prediction 1).-The numbers of nests (log-transformed) inside the plots and in the outer bands were compared between months, treatments (control vs. experimental $=$ density-reduced), and their interaction, using GLMM.

Nearest neighbor analysis (prediction 2).-The average nearest neighbor distance was calculated for nests located in the areas formed by the plots and the outer bands after each exhaustive mapping. This was compared to the distance expected if nests were randomly distributed (Clark and Evans 1954) using a GLMM in which the response variable was the ratio between the observed and the expected distance (nearest neighbor ratio, NNR) minus 1 . Month and treatment were the explanatory variables. The significance of the model intercept indicated whether the NNR was significantly greater (overdispersion) or smaller (aggregation) than 1. Nonsignificant intercept indicated random distribution.

Foraging distance (prediction 3).- The maximum foraging distance (MFD) of a colony was estimated as the distance between a nest and the furthest bait where at least one of its workers was foraging. MFDs averaged per plot and month constituted the raw data to which the GLMM were fitted, using treatment, month, and their interaction as fixed effects. Different models were fitted for colonies located inside the plots and in the outer bands.

Migrations (prediction 4).-The Wilcoxon test for unpaired data was employed to compare the following variables between control and experimental plots: (1) number of migrations of nests located in the outer bands during the first 18 weeks; (2) the probability of migration of focal colonies per week until 12 July 2007 or until the focal colony was lost (the number of recorded migrations divided by the number of weeks of census); and (3) the net colony influx (the difference between the number of inward and outward migrations) during the first 18 weeks. 
TABLE 1. Results of general linear mixed models conducted on different variables measured in control and density-reduced plots of the ant Aphaenogaster senilis throughout the experiment at the research reserve of the Donana National Park, Spain.

\begin{tabular}{|c|c|c|c|c|c|}
\hline Response variable, fixed effects & df & $F$ & $P$ & Random effects & Variance $(\%)$ \\
\hline \multicolumn{6}{|l|}{ Number of nests inside the plots } \\
\hline Intercept & 1,168 & 75.99 & $<0.0001$ & & \\
\hline Treatment & 1,25 & 15.69 & $<0.0001$ & demes & 40.0 \\
\hline Month & 6,168 & 28.52 & $<0.0001$ & plots within demes & 32.7 \\
\hline Treatment: month & 6,168 & 18.59 & $<0.0001$ & residual & 27.3 \\
\hline \multicolumn{6}{|l|}{ Number of nests in the outer band } \\
\hline Intercept & 1,168 & 34.19 & $<0.0001$ & & \\
\hline Treatment & 1,25 & 0.09 & 0.7707 & demes & 35.6 \\
\hline Month & 6,168 & 8.94 & $<0.0001$ & plots within demes & 36.3 \\
\hline Treatment: month & 6,168 & 0.48 & 0.8213 & residual & 28.1 \\
\hline \multicolumn{6}{|l|}{ NNR } \\
\hline Intercept & 1,168 & 151.18 & $<0.0001$ & & \\
\hline Treatment & 1,25 & 3.02 & 0.0945 & demes & 0.00 \\
\hline Month & 6,168 & 4.67 & 0.0002 & plots within demes & 50.1 \\
\hline Treatment: month & 6,168 & 2.46 & 0.0261 & residual & 49.9 \\
\hline \multicolumn{6}{|l|}{ MFD of nests located inside the plots } \\
\hline Intercept & 1,167 & 25.29 & $<0.0001$ & & \\
\hline Treatment & 1,25 & 10.34 & 0.0036 & demes & 49.3 \\
\hline Month & 6,167 & 15.25 & $<0.0001$ & plots within demes & 16.0 \\
\hline Treatment: month & 6,167 & 2.95 & 0.0091 & residual & 34.7 \\
\hline \multicolumn{6}{|l|}{ MFD of nests located in the outer band } \\
\hline Intercept & 1,167 & 37.05 & $<0.0001$ & & \\
\hline Treatment & 1,25 & 7.59 & 0.0108 & demes & 47.1 \\
\hline Month & 6,167 & 10.44 & $<0.0001$ & plots within demes & 16.3 \\
\hline Treatment: month & 6,167 & 5.89 & 0.0001 & residual & 36.7 \\
\hline \multicolumn{6}{|l|}{ Relatedness } \\
\hline Intercept & 1,80 & 1592.57 & $<0.0001$ & demes & 0.1 \\
\hline Treatment & 1,18 & 0.36 & 0.5594 & plots within demes & \\
\hline Cohort & 2,80 & 25.11 & $<0.0001$ & nests within plots & 0.1 \\
\hline Treatment: cohort & 2,80 & 3.98 & 0.0224 & residual & 99.8 \\
\hline
\end{tabular}

Note: Key to abbreviations: NNR, nearest neighbor ratio; MFD, maximum foraging distance. Demes are the four different subpopulations (Comedero, Visita, Beles, and Jaulon) where the study was conducted.

Colony productivity (prediction 5).-The total fresh biomasses of focal colonies were compared between experimental and control plots before the onset of the experiment $\left(M_{-1}\right)$ and at $M_{3}$ (July 2007) using Wilcoxon test for unpaired data. In addition, the proportion of resource allocation for production of workers vs. males was estimated by comparing the ratios of male (including adults and pupae) to worker pupae biomasses between control and experimental plots.

Colony reproduction (prediction 6 ).--For each colony the relatedness within and, whenever possible, between cohorts was estimated using Relatedness 5.0.1 (Queller and Goodnight 1997). Preliminary analyses indicated that there was no evidence of deviation from HardyWeinberg expectation or linkage disequilibrium for these loci and that they could be considered independent (Galarza et al. 2009). Relatedness was then compared between treatments (control vs. experimental) and cohorts (three levels: worker-worker, pupae-pupae, worker-pupae) by fitting a GLMM. The 32 colonies that were excavated in late April-early May 2008 were considered daughter colonies if the genetic relatedness between workers and pupae was significantly lower than
0.75. Their size was compared between experimental and control plots using the Wilcoxon test.

\section{RESULTS \\ Nest density}

Nest removal in the experimental plots was followed by a rapid recovery of population, thus confirming prediction 1 . The number of nests inside the plots varied significantly between treatments, months, and their interaction (Table 1). Initially $\left(M_{-1}\right)$, control and experimental plots contained on average $5.6 \pm 0.8$ and $5.8 \pm 0.5$ nests, respectively (Fig. $1 \mathrm{~A} ; t_{25}=0.59, P=$ $0.56)$. In the control plots, the number of nests did not vary significantly during the six following exhaustive censuses (Fig. 1A). By contrast, nest removal in April 2007 provoked a significant reduction of nest number in the experimental plots compared to the controls (Fig. $1 \mathrm{~A} ; 1.2 \pm 0.1$ nests including the focal colonies vs. $5.3 \pm$ 0.5 nests in experimental and control plots, respectively; $\left.t_{25}=-6.85, P<0.0001\right)$. The number of nests in the experimental plots remained significantly lower than in the control plots in May, June, and August 2007 (Fig. $1 \mathrm{~A} ; t_{25}=-5.83, P<0.0001, t_{25}=-4.66, P=0.0001$ and $t_{25}=-3.19, P=0.0037$, respectively). However, in 


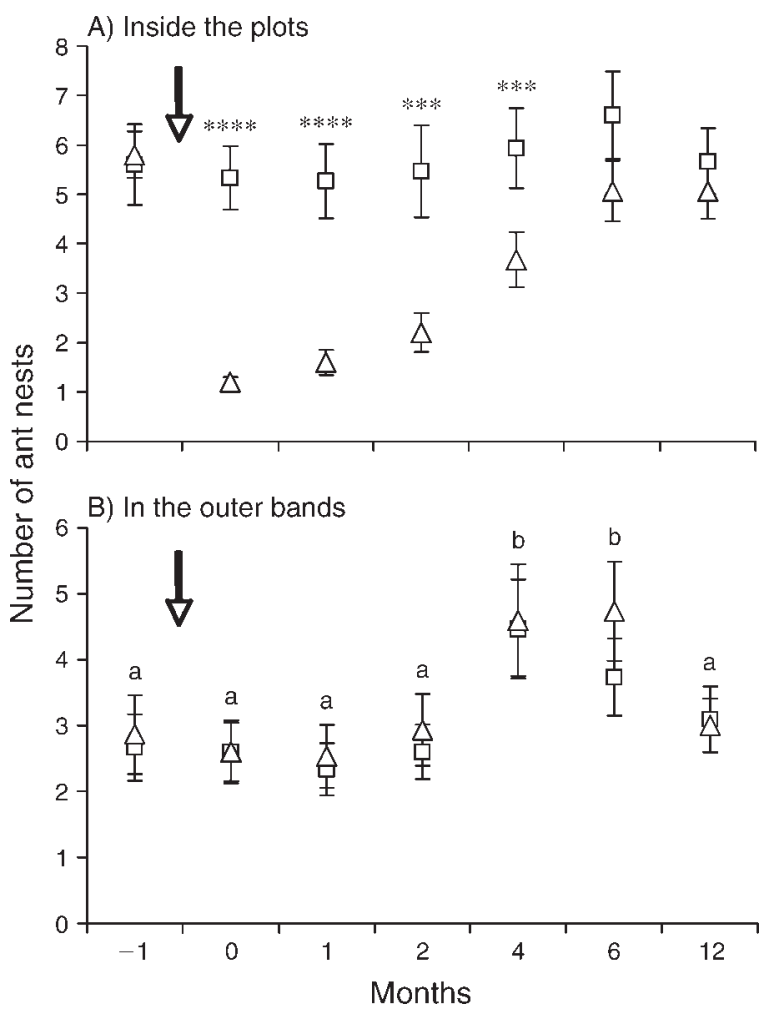

FIG. 1. Number of ant (Aphaenogaster senilis) nests (mean \pm SE) (A) inside the plots and (B) in the outer bands. Squares and triangles represent control and experimental plots, respectively. Reduction of nest density in experimental plots was effected between March and April 2007 (arrow). Asterisks denote significant differences between treatment and control plots for each month separately. Different lowercase letters denote significant differences $(P<0.05)$ between months for treatment and control plots, considered together. Month -1 indicates the number of nests in experimental and control plots one month before nest reduction.

*** $P<0.001 ; * * * * P<0.0001$

October $2007\left(M_{6}\right)$ and April $2008\left(M_{12}\right)$ nest numbers inside the experimental and control plots were no longer significantly different $\left(t_{25}=-1.78, P=0.09\right.$ and $t_{25}=$ $-0.65, P=0.52$ at $M_{6}$ and $M_{12}$, respectively).

In the outer band, there were $2.7 \pm 0.5$ and $2.9 \pm 0.6$ nests in the control and experimental plots, respectively at $M_{-1}\left(t_{25}=0.13, P=0.90\right)$. Although the number of nests outside the plots increased significantly at $M_{4}$ and $M_{6}$ with respect to the initial level at $M_{-1}\left(t_{174}=4.32, P\right.$ $<0.0001$ and $t_{174}=3.99, P=0.0001$, respectively), it did not differ significantly between the control and experimental plots (Fig. 1B, Table 1).

\section{Nest distribution}

In March 2007, the average distance between two nearest neighbor nests was $6.4 \pm 0.4 \mathrm{~m}$. Given the surface of the plots plus the outer band $\left(441 \mathrm{~m}^{2}\right)$ and nest numbers at this time, this distance was higher than expected if the nests were distributed randomly $(4.9 \pm$ $0.2 \mathrm{~m} ; \mathrm{NNR}=1.31 \pm 0.06$, significantly higher than 1 , $\left.t_{168}=5.43, P<0.0001\right)$. The NNR in the control plots did not vary significantly throughout the experiment and remained higher than 1 . In the experimental plots, the NNR before nest removal $(1.34 \pm 0.05)$ was also significantly higher than $1\left(t_{168}=5.98, P<0.0001\right)$ and nonsignificantly different from the control plots $\left(t_{25}=\right.$ $0.38, P=0.70)$. Nest removal provoked a significant increase of NNR in the first two months. At $M_{2}$ NNR returned to a level nonsignificantly different from that before the manipulation. However, on no occasion were the nests randomly distributed or aggregated, which confirmed prediction 2 .

\section{Foraging distance}

Prediction 3 was also confirmed: colony foraging span increased significantly after density reduction. In March $2007\left(M_{-1}\right)$, the MFD of nests located inside control and experimental plots was $3.9 \pm 0.4 \mathrm{~m}$ and $4.2 \pm 0.3 \mathrm{~m}$, respectively (Fig. 2A; $t_{25}=0.46, P=0.65$ ). Overall, it was higher in experimental than in control plots and varied between months depending on treatments (Table

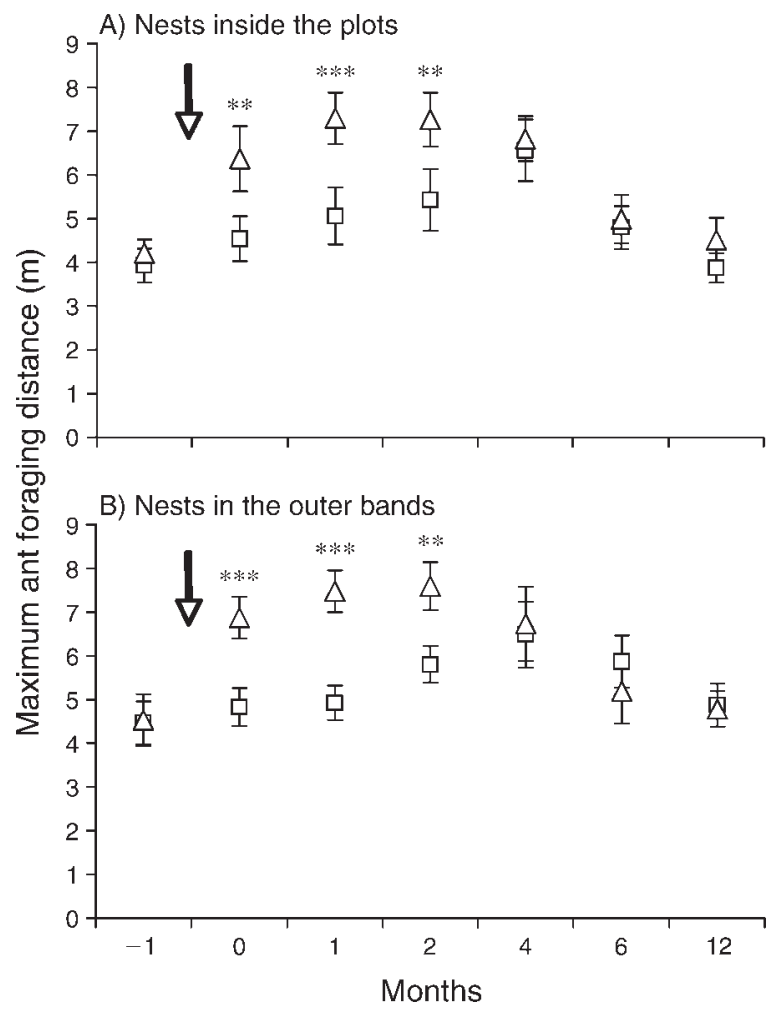

FIG. 2. Maximum ant foraging distance (mean $\pm \mathrm{SE})$ in control (squares) and experimental plots (triangles) (A) inside the plots and (B) in the outer bands. Reduction of nest density in experimental plots was effected between March and April 2007 (arrow). Asterisks denote significant differences between experimental and control plots for each month separately. Month -1 indicates the maximum foraging distance in experimental and control plots one month before nest reduction.

$$
\text { ** } P<0.01 ; * * * P<0.001 \text {. }
$$




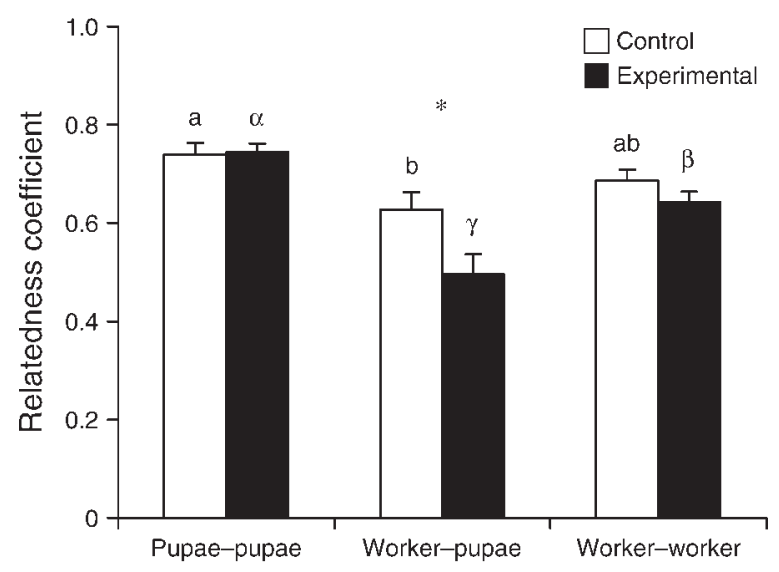

FIG. 3. Relatedness coefficients (mean $+\mathrm{SE}$ ) within and between ant cohorts. Different lowercase letters and Greek symbols denote significant differences among control and experimental plots, respectively. Asterisk denotes significant differences between treatments within cohorts.

* $P<0.05$

1). Hence, in control plots, the MFD of nests located inside the plots was significantly higher at $M_{1}, M_{2}$, and $M_{4}$, but not at $M_{0}, M_{6}$, and $M_{12}$, compared to $M_{-1}$ (Fig. $2 \mathrm{~A} ; t_{167}=2.08, P=0.0387 ; t_{167}=2.78, P=0.0063 ; t_{167}=$ 4.83, $P<0.0001, M_{1}, M_{2}$, and $M_{4}$, respectively, and $t_{167}$ $=1.12, P=0.26, t_{167}=1.60, P=0.11$ and $t_{167}=-0.09, P$ $=0.9239$, for $M_{0}, M_{6}$, and $M_{12}$, respectively). In the experimental plots, the MFD increased earlier than in control plots. The differences between experimental and control plots were significant at $M_{0}\left(t_{25}=3.05, P=\right.$ $0.0053), M_{1}\left(t_{25}=4.02, P=0.0005\right)$, and $M_{2}\left(t_{25}=3.05\right.$, $P=0.0053)$ but not at $M_{4}\left(t_{25}=0.44, P=0.66\right), M_{6}\left(t_{25}=\right.$ $0.31, P=0.75)$, and $M_{12}\left(t_{25}=1.06, P=0.30\right)$.

Similar to the nests located inside the plots, the MFD of nests located outside the plots varied significantly according to the treatment, the month, and their interaction (Table 1, Fig. 2B). At $M_{-1}$, the MFD of outside nests did not differ significantly between experimental and control plots $\left(t_{25}=0.11, P=0.92\right)$. In control plots, the MFD increased significantly at $M_{2}$, $M_{4}$, and $M_{6}\left(t_{167}=2.55, P<0.0118, t_{167}=3.83, P<\right.$ 0.0002 and $t_{167}=2.67, P<0.0084$, respectively) while in experimental plots, it increased earlier in the season, at $M_{0}, M_{1}, M_{2}\left(t_{25}=3.54, P=0.0016 ; t_{25}=5.59, P=\right.$ $0.0001 ; t_{25}=3.11, P=0.0047$, respectively).

\section{Nest migrations}

Prediction 4 was not supported by the obtained data. On average, $21 \pm 3$ and $22 \pm 3$ migrations were recorded in the outer band between 5 April 2007 and 2 August 2007 in control and experimental plots, respectively (Wilcoxon test: $W=98, P=0.57$ ). Given the number of nests per plot, this means that $\sim 20 \%$ of the colonies had changed nests per week throughout the study. Focal nests did not migrate more often in experimental than in control plots $(0.25 \pm 0.01$ vs. $0.19 \pm 0.01$ migration per week and focal colony; Wilcoxon test: $W=84, P=0.25$ ).
Considering colony relocation of $<3 \mathrm{~m}$, the net influx of nests in the experimental plots was inward $(0.73 \pm 0.43)$, while that in the control plots was slightly outward $(-0.07 \pm 0.39)$, but this difference was not statistically significant (Wilcoxon test: $W=79, P=0.16$ ).

\section{Colony productivity}

Prediction 4 was partially confirmed: in March 2007, the focal colonies contained mostly workers and small larvae but no pupae or males. Their entire fresh biomass was not significantly different between control and experimental plots $(9.25 \pm 1.06 \mathrm{~g}$ and $8.68 \pm 1.04 \mathrm{~g}$, respectively; Wilcoxon test: $W=33, P=0.91)$. Unlike our prediction the focal colonies biomass at $\mathrm{M}_{3}$, was not statistically significant in control and in experimental plots $(9.80 \pm 3.27 \mathrm{~g}$ and $11.22 \pm 3.74 \mathrm{~g}$, respectively; Wilcoxon test: $W=26, P=0.60)$. The increase in biomass between $M_{-1}$ and $M_{3}$ was significant neither for control nor for experimental plots (Wilcoxon test: $W=$ $39, P=0.93$ and $W=17, P=0.38$, respectively). However, as predicted, the resource allocation within colonies differed significantly between the control and experimental groups. In effect, the ratio of biomasses of males over worker pupae was significantly higher in control than in experimental plots $(0.85 \pm 0.55 \mathrm{~g}$ and $0.01 \pm 0.00 \mathrm{~g}$, respectively; Wilcoxon test: $W=56$, $P=0.02)$.

\section{Colony reproduction}

All microsatellite loci analyzed ranged from being moderate to highly polymorphic, showing an average of 14.8 alleles/locus (Asen12 [13 alleles], Asen 15 [5 alleles], Asen58 [7 alleles], Asen83 [16 alleles], Asen94 [16 alleles], Asen 155 [20 alleles], Asen178 [17 alleles], and Ms2D [25 alleles]). In control plots, the average relatedness among pupae and that among adult workers were not significantly different from 0.75 , the expected relatedness among full sisters in a monogynous, monandrous species (Fig. 3, Table 1). Both in control and experimental plots, relatedness between pupae and workers was significantly lower than among pupae and than among workers (Fig. 3). However, the reduction in relatedness between cohorts was significantly more pronounced in densityreduced than in control plots (Fig. 3; $t_{94}=-2.70$, $P=0.0080)$.

Of the 32 colonies collected in the month following the end of the experiment, only 17 colonies were unequivocally identified as daughter colonies (workerpupae relatedness was significantly smaller than 0.75 in 10 and 7 colonies in density-reduced and control plots, respectively). They all had a non-marked queen. Their worker biomass was significantly smaller in experimental than in control plots $(3.50 \pm 0.42 \mathrm{~g}$ vs. $6.13 \pm 0.48 \mathrm{~g}$; $W=65, P=0.002)$. In contrast, the brood biomass was not significantly different between treatments $(5.32 \pm$ $0.67 \mathrm{~g}$ vs. $3.24 \pm 0.20 \mathrm{~g} ; W=17, P=0.11$ ). These results reveal that in the experimental plots there were more colonies that had derived from recent fission, and that 
they were composed of fewer workers than in control plots, which confirms prediction 6 .

\section{Discussion}

The results of the present study reveal the importance of intraspecific competition for the regulation of populations of A. senilis. As predicted (prediction 1), density reduction in the 15 experimental plots was followed by a rapid recovery in the number of nests. In less than one year density had returned to a level similar to that of control plots. Such resilience is not expected in populations regulated by density-independent phenomena (Murdoch 1970, 1994). Moreover, in both the control and experimental plots nests remained overdispersed throughout the experiment (prediction 2), suggesting that neighbors compete for space-linked resources and exclude each other. Worker ants, including $A$. senilis, are able to discriminate and aggress nonnestmates (Ichinose et al. 2005, 2009), and on several occasions during the course of the experiment we noticed aggression among foragers. In particular, we often observed ants from a colony that had dominated a bait chasing away intruders through violent aggression. Aggressive encounters among neighbors may therefore limit colony foraging span. Even in the absence of direct interference interactions, a colony may systematically remove resources in its vicinity, thus reducing its attractiveness for neighbors (Adler and Gordon 2003). This is also supported by the rapid increase of foraging span exhibited by the colonies that remained in the experimental plots (prediction 3; Fig. 2). In August, the temporary expansion of foraging span in the control plots may have been due to enhanced motivation to discover food items which are scarcer during the hot season.

Prediction 4 hypothesized that reducing intraspecific competition would allow nests to migrate more often and, for those located outside the plots, to migrate inward. However, the results give little credence to this hypothesis. During the first 18 weeks there were no significant differences between plots, either in the total number of migrations, or in the probability of migrations of focal colonies, nor the net colony influx. This suggests that migrations played only a limited role during the process of population recovery, in contrast to the findings of Adams and Tschinkel (2001), who demonstrated that upon colony removal in $S$. invicta, neighbors progressively moved to the center of the plots. One explanation for such differences is that colony movement in the genus Aphaenogaster may be either motivated or constrained by various kinds of perturbations, including ground temperature (Smallwood 1982) and predator attacks (McGlynn et al. 2004). Interestingly, Smallwood (1982) found that food supplementation did not significantly affect the probability of migration in $A$. rudis, suggesting that intraspecific competition does not determine colony movement in this species.
There was no significant increase in the focal colonies' total biomass during the first four months of the experiment in less crowded conditions. However, as predicted (prediction 5) resource allocation for male and worker production differed significantly between experimental and control plots, redirecting part of the resources that colonies would have normally allocated to the production of males, to the production instead of workers in response to the lack of neighbors. In $V$. pergandei and P. californicus, Ryti and Case (1988) demonstrated that the removal of neighbors provoked an increase in the production of both males and queens relative to workers. In these species, both sexes disperse individually, so the lack of competitors is expected to favor both sexes equally. In contrast, in $A$. senilis females disperse with part of their mother colony over much shorter distances than males. Thus, under normal nest density in which female units inevitably compete among relatives, males are highly valuable and are produced in relatively large numbers. Nevertheless, under less crowded conditions, reduced competition among female units enhances the value of colony fission. Consequently, because a larger worker force is needed for successful fission, adult colonies in experimental plots may have had to allocate a lesser amount of resources for male production in favor of greater worker production. Proximately, such a shift in the allocation of resources may have resulted from a qualitative change in colonies' resource intake, such as an increase in the proportion of proteins or lipids, which is known to affect the production of sexuals, as well as the sex ratio in other species (Deslippe and Savolainen 1995, Bono and Herbers 2003, Brown and Keller 2006). In A. senilis, queens are produced in very small numbers and only in large or queenless colonies (Boulay et al. 2007b). It has been suggested that queens are actually produced only after fission (Ledoux 1971), which explains why we did not find unmated queens in the colonies excavated just before the reproductive season.

Molecular data supported prediction 6, that is, that population recovery was due to an enhanced rate of reproduction. At the end of the experiment in April 2008 the average relatedness between workers and pupae was lower in the experimental than in the control plots. Asymmetry in relatedness between and within cohorts is expected if pupae are not the sisters of the workers but are their nieces, either because the old queen had died and been replaced by one of her daughters (queen replacement hypothesis), or because the mother colony had split the year before (reproduction hypothesis). In the latter case, the relatedness between cohorts is expected to remain 0.75 in the mother colony (that part of the colony that retains the old queen) but to drop to 0.375 in the new nests. Although some queens may have died during the year of the experiment, the queen replacement hypothesis is unlikely to explain the significant drop in worker-pupae relatedness in the 
experimental plots, because there is no reason to expect higher queen mortality in these plots than in the controls. Therefore, this drop in relatedness more likely resulted from the production of numerous new nests by existing colonies. The reproduction hypothesis is further supported by the fact that the onset of recovery to normal nest density in the experimental plots coincided with the period of fission, which in $A$. senilis starts in mid-summer (Boulay et al. 2009). Finally, colonies that derived from fission after density reduction contained fewer workers than those produced in control plots. This suggests that in the absence of competitors, the remaining colonies tended to reproduce more rapidly or to produce a higher number of buds than under crowded conditions, resulting in recovery to the initial number of nests. Normally, under crowded conditions a society may have to reach a threshold size before undergoing fission, so as to guarantee the success of the daughter colony without jeopardizing survival of the mother colony (Strassmann et al. 1997, Al-Khafaji et al. 2009). However, under less crowded conditions, this threshold may be lowered because the first daughter colonies that reach free areas face little competition and, furthermore, are likely to have an important ecological advantage over their future competitors.

In conclusion, our results indicate that intraspecific competition limits population growth in the ant $A$. senilis. Under density-reduced conditions, colonies tend to allocate more resources to the production of workers, which allows them to rapidly undergo fission with a subsequent increase in nest numbers. Moreover, earlier fission enables daughter colonies to rapidly occupy empty areas, providing them with an important ecological advantage. Our study empirically demonstrates that ant populations are regulated by density, and that they can adapt the magnitude of resource allocation for producing male and female offspring to the level of intraspecific competition.

\section{ACKNOWLEDGMENTS}

We are grateful to I. Luque and A. Carvajal for their important assistance both in the field and in the laboratory. E. Angulo, D. Feener, J.-C. Lenoir, C. Pérez, and T. Monnin provided help in the field. D. Aragonés from the LAST-EBD assisted us with spatial data. T. Monnin and C. Doums discussed the experimental design. P. Nonacs and an anonymous referee provided important comments on the first version of this manuscript. This project was financed by project no. CGL2006-04968/BOS, and FEDER to R. Boulay and X. Cerdá. A. Hefetz was supported by a Spanish sabbatical fellowship from Ministerio de Educación y Ciencia (SAB20050158). We thank the authorities of Doñana National Park for providing permits and facilities to conduct this study, and Naomi Paz, Tel Aviv University, for editorial assistance. All experiments comply with the current Spanish laws.

\section{Literature Cited}

Adams, E. S., and W. R. Tschinkel. 1995a. Effects of foundress number on brood raids and queen survival in the fire ant Solenopsis invicta. Behavioral Ecology and Sociobiology 37: 233-242.
Adams, E. S., and W. R. Tschinkel. 1995b. Spatial dynamics of colony interactions in young populations of the fire ant Solenopsis invicta. Oecologia 102:156-163.

Adams, E. S., and W. R. Tschinkel. 2001. Mechanisms of population regulation in the fire ant Solenopsis invicta: an experimental study. Journal of Animal Ecology 70:355-369.

Adler, F. R., and D. M. Gordon. 2003. Optimization, conflict, and nonoverlapping foraging ranges in ants. American Naturalist 162:529-543.

Al-Khafaji, K., S. Tuljapurkar, J. R. Carey, and R. E. Page. 2009. Hierarchical demography: a general approach with an application to honey bees. Ecology 90:556-566.

Amundsen, P. A., R. Knudsen, and A. Klemetsen. 2007. Intraspecific competition and density dependence of food consumption and growth in Arctic charr. Journal of Animal Ecology 76:149-158.

Arthofer, W., B. C. Schlick-Steiner, and F. M. Steiner. 2005. Isolation of polymorphic microsatellite loci for the study of habitat fragmentation in the harvester ant Messor structor. Conservation Genetics 6:859-861.

Balbontín, J., and M. Ferrer. 2008. Density-dependence by habitat heterogeneity: individual quality versus territory quality. Oikos 117:1111-1114.

Berryman, A. A. 2004. Limiting factors and population regulation. Oikos 105:667-670.

Billick, I., D. C. Wiernasz, and B. J. Cole. 2001. Recruitment in the harvester ant, Pogonomyrmex occidentalis: effects of experimental removal. Oecologia 129:228-233.

Bono, J. M., and J. M. Herbers. 2003. Proximate and ultimate control of sex ratios in Myrmica brevispinosa colonies. Proceedings of the Royal Society of London B 270:811-817.

Boulay, R., X. Cerdá, A. Fertin, K. Ichinose, and A. Lenoir. 2009. Brood development into sexual females depends on the presence of a queen but not on temperature in an ant dispersing by colony fission, Aphaenogaster senilis. Ecological Entomology 34:595-602.

Boulay, R., X. Cerdá, T. Simon, M. Roldan, and A. Hefetz. 2007a. Intraspecific competition in the carpenter ant Camponotus cruentatus: should we expect the dear enemy effect? Animal Behaviour 74:985-993.

Boulay, R., A. Hefetz, X. Cerdá, S. Devers, W. Francke, R. Twele, and A. Lenoir. 2007b. Production of sexuals in a fission-performing ant: dual effects of queen pheromones and colony size. Behavioral Ecology and Sociobiology 61:15311541.

Bourke, A. F. G., and N. R. Franks. 1995. Social evolution in ants. Princeton University Press, Princeton, New Jersey, USA.

Branson, D. H. 2008. Influence of a large late summer precipitation event on food limitation and grasshopper population dynamics in a northern Great Plains grassland. Environmental Entomology 37:686-695.

Brown, W. D., and L. Keller. 2006. Resource supplements cause a change in colony sex-ratio specialization in the mound-building ant, Formica exsecta. Behavioral Ecology and Sociobiology 60:612-618.

Carrete, M., J. L. Tella, J. A. Sanchez-Zapata, M. Moleon, and J. M. Gil-Sanchez. 2008. Current caveats and further directions in the analysis of density-dependent population regulation. Oikos 117:1115-1119.

Charnov, E. L. 1982. The theory of sex allocation. Princeton University Press, Princeton, New Jersey, USA.

Chéron, B., C. Doums, P. Federici, and T. Monnin. 2009. Queen replacement in the monogynous ant Aphaenogaster senilis: supernumerary queens as life insurance. Animal Behaviour 78:1317-1325.

Clark, P. J., and J. D. Evans. 1954. Distance to nearest neighbor as a measure of relationships in populations. Ecology 35:445-453. 
Cole, B. J., and D. C. Wiernasz. 2002. Recruitment limitation and population density in the harvester ant, Pogonomyrmex occidentalis. Ecology 83:1433-1442.

Crozier, R. H., and P. Pamilo. 1996. Evolution of social insect colonies, sex allocation and kin selection. Oxford University Press, Oxford, UK.

Cushman, J. H., G. D. Martinsen, and A. I. Mazeroll. 1988. Density- and size-dependent spacing of ant nests: evidence for intraspecific competition. Oecologia 77:522-525.

Deslippe, R. J., and R. Savolainen. 1995. Sex investment in a social insect: the proximate role of food. Ecology 76:375-382.

De Vita, J. 1979. Mechanisms of interference and foraging among colonies of the harvester ant Pogonomyrmex californicus in the Mojave Desert. Ecology 60:729-737.

Elmes, G. W. 1974. The spatial distribution of a population of two ant species living in limestone grassland. Pedobiologia 14:412-418.

Galarza, J. A., R. Boulay, X. Cerdá, C. Doums, P. Federici, H. Magalon, T. Monnin, and C. Rico. 2009. Development of single sequence repeat markers for the ant Aphaenogaster senilis and cross-species amplification in A. iberica, A. gibbosa, A. subterranea and Messor maroccanus. Conservation Genetics 10:519-521.

Gordon, D. M. 1997. The population consequences of territorial behavior. Trends in Ecology and Evolution 12: 63-66.

Gordon, D. M., and A. Kulig. 1998. The effect of neighbours on the mortality of harvester ant colonies. Journal of Animal Ecology 67:141-148.

Gordon, D. M., and D. Wagner. 1997. Neighborhood density and reproductive potential in harvester ants. Oecologia 109: $556-560$.

Hamilton, W. D. 1967. Extraordinary sex ratios. Science 156: 477-488.

Honarvar, S., M. P. O'Connor, and J. R. Spotila. 2008. Density-dependent effects on hatching success of the olive ridley turtle, Lepidochelys olivacea. Oecologia 157:221-230.

Ichinose, K., R. Boulay, X. Cerdá, and A. Lenoir. 2009. Queen and diet influence on nestmate recognition and cuticular hydrocarbon differentiation in a fission-performing ant, Aphaenogaster senilis. Zoological Science 27:475-481.

Ichinose, K., X. Cerdá, J.-P. Cristede, and A. Lenoir. 2005. Detecting nestmate recognition patterns in the fissionperforming ant Aphaenogaster senilis: a comparison of different indices. Journal of Insect Behavior 18:633-650.

Iguchi, K., and T. Hino. 1996. Effect of competitor abundance on feeding territoriality in a grazing fish, the ayu Plecoglossus altivelis. Ecological Research 11:165-173.

Krebs, C. J. 2002. Two complementary paradigms for analyzing population dynamics. Philosophical Transactions of the Royal Society 357:1211-1219.

Ledoux, A. 1971. Un nouveau mode de bouturage de société chez la fourmi Aphaenogaster senilis Mayr. Comptes Rendus Hebdomadaires des Séances de l'Académie des Sciences, Série D Sciences Naturelles 273:83-85.

Leips, J., J. M. L. Richardson, F. H. Rodd, and J. Travis. 1997. Adaptative maternal adjustments of offspring size in response to conspecific density in two populations of the least killifish, Heterandria formosa. Evolution 63:1341-1347.
López-Sepulcre, A., and H. Kokko. 2005. Territorial defense, territory size, and population regulation. American Naturalist $166: 317-329$.

Massot, M., J. Clobert, T. Pilorge, J. Lecomte, and R. Barbault. 1992. Density dependence in the common lizard: demographic consequences of a density manipulation. Ecology 73:1742-1756.

McGlynn, T. P., R. A. Carr, J. H. Carson, and J. Buma. 2004. Frequent nest relocation in the ant Aphaenogaster araneoides: resources, competition, and natural enemies. Oikos 106:611621.

Murdoch, W. W. 1970. Population regulation and population inertia. Ecology 51:497-502.

Murdoch, W. W. 1994. Population regulation in theory and practice. Ecology 75:272-287.

Nilsson, P. A. 2006. Avoid your neighbours: size-determined spatial distribution patterns among northern pike individuals. Oikos 113:251-258.

Pellet, J., B. R. Schmidt, F. Fivaz, N. Perrin, and K. Grossenbacher. 2006. Density, climate and varying return points: an analysis of long-term population fluctuations in the threatened European tree frog. Oecologia 149:65-71.

Queller, D. C., and K. F. Goodnight. 1997. Relatedness version 5.0. Keck Center for Computation Biology, Rice University, Houston, Texas, USA.

R Development Core Team. 2009. R: a language and environment for statistical computing. R Foundation for Statistic Computing, Vienna, Austria. 〈http://www. R-project.org

Ryti, R. T., and T. J. Case. 1986. Overdispersion of ant colonies: a test of hypotheses. Oecologia 69:446-453.

Ryti, R. T., and T. J. Case. 1988. Field experiment on desert ants: testing for competition between colonies. Ecology 69: 1993-2003.

Sæther, B. E., T. H. Ringsby, Ø. Bakke, and E. J. Solberg. 1999. Spatial and temporal variation in the demography of a house sparrow metapopulation. Journal of Animal Ecology 68: 628-637.

Sanders, N. J., and D. M. Gordon. 2004. The interactive effects of climate, life history, and interspecific neighbours on mortality in a population of seed harvester ants. Ecological Entomology 29:632-637.

Smallwood, J. 1982. The effect of shade and competition of emigration rate in the ant Aphaenogaster rudis. Ecology 63: 124-134.

Stearns, S. C. 2000. Life history evolution: successes, limitations and prospects. Naturwissenschaften 87:476-486.

Strassmann, J. E., C. R. Solis, C. R. Hughes, K. F. Goodnight, and D. C. Queller. 1997. Colony life history and demography of a swarm-founding social wasp. Behavioral Ecology and Sociobiology 40:71-77.

Therrien, J. F., S. D. Cote, M. Festa-Bianchet, and J. P. Ouellet. 2007. Conservative maternal care in an iteroparous mammal: a resource allocation experiment. Behavioral Ecology and Sociobiology 62:193-199.

Waelti, M. O., and H. U. Reyer. 2007. Food supply modifies the trade-off between past and future reproduction in a sexual parasite-host system (Rana esculenta, Rana lessonae). Oecologia 152:415-424. 